\title{
Temporary Unilateral Neurogenic Blepharoptosis after Orbital Medial Wall Reconstruction: 3 Cases
}

\author{
Jee Woong Jung Mi Jung Chi \\ Department of Ophthalmology, Gachon University, Gil Medical Center, Incheon, Korea
}

\section{Key Words}

Orbital wall reconstruction, complication - Neurogenic blepharoptosis $\cdot$ Ptosis

\begin{abstract}
Purpose: We report 3 cases of unilateral blepharoptosis after orbital medial wall reconstruction and describe the cause and clinical outcome. Methods: Observational case series. Results: Three previously healthy patients underwent reconstruction for orbital medial wall fracture. All 3 patients had complete unilateral upper eyelid ptosis with no levator palpebrae superioris muscle function immediately after their recovery from anesthesia. Additional findings included minimal eyelid ecchymosis, eyelid edema and subconjunctival hemorrhage, which all presented preoperatively. All 3 patients had full conjugated ocular motility in the entire field of gaze and no anisocoria. With oral steroid therapy, all 3 patients recovered completely with normal symmetric lid height and levator function within 1 month. Conclusion: Isolated neurogenic blepharoptosis after medial orbital wall reconstruction is a rare but favorable disease that may result from ischemic damage at the end portion of the superior branch of the oculomotor nerve in the orbit. High-dose steroid therapy early in the course of the disease was effective, and complete resolution was achieved within 1 month.
\end{abstract}

Copyright $\odot 2008$ S. Karger AG, Basel

\begin{tabular}{|c|c|}
\hline KARGER & $\begin{array}{l}\text { (c) } 2008 \text { S. Karger AG, Basel } \\
0030-3755 / 08 / 2225-0360 \$ 24.50 / 0\end{array}$ \\
\hline $\begin{array}{l}\text { Fax +4161306 } 1234 \\
\text { E-Mail karger@karger.ch } \\
\text { www.karger.com }\end{array}$ & $\begin{array}{l}\text { Accessible online at: } \\
\text { www.karger.com/oph }\end{array}$ \\
\hline
\end{tabular}

\section{Introduction}

Neurogenic blepharoptosis induced by peripheral oculomotor nerve injury is rare and occasionally occurs due to eyelid trauma [1] or compressive lesions, such as pituitary tumors [2,3] or cerebral aneurysms [4]. We describe 3 patients with complete blepharoptosis after reduction for blowout fracture on the medial wall. To our knowledge, this is the first report of isolated unilateral neurogenic blepharoptosis following orbital wall reconstruction.

\section{Case Report}

Three previously healthy patients (1 male, 2 female; aged $30-$ 41 years) underwent reconstruction of an orbital medial wall fracture. The orbital wall reconstruction was performed under general anesthesia via the transcaruncular approach using endoscopy and Medpor ${ }^{\circledR}$ barrier sheet implantation after the reduction of the fracture. They had unilateral complete upper eyelid ptosis with no levator palpebrae superioris muscle function immediately after their recovery from anesthesia. Additional findings included minimal eyelid ecchymosis, eyelid edema and subconjunctival hemorrhage which all presented preoperatively. All 3 patients had full conjugated ocular motility in the entire field of gaze and no anisocoria (fig. 1). They received oral prednisolone at a dosage of $1 \mathrm{mg} / \mathrm{kg}$ per day for 4 days with gradual tapering off (10 mg for 4 days) and discontinuation. In order to evaluate the change of the lid state in these 3 patients with ptosis, the marginal-reflex distance 1, vertical fissure height and levator function 

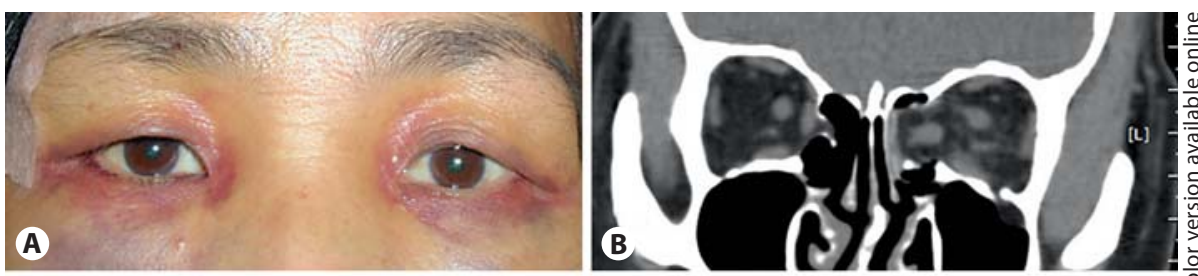

Fig. 1. Left upper eyelid ptosis 1 day after orbital wall reconstruction. A Mild edema and ptosis on the left upper eyelid before surgery. B Preoperative coronal CT scan photograph; the size of the fracture was so large as to reach the superior orbital wall. C, D Complete absence of left levator muscle function in primary gaze and upgaze. E Preservation of superior rectus function, demonstrated with mechanical eyelid elevation.
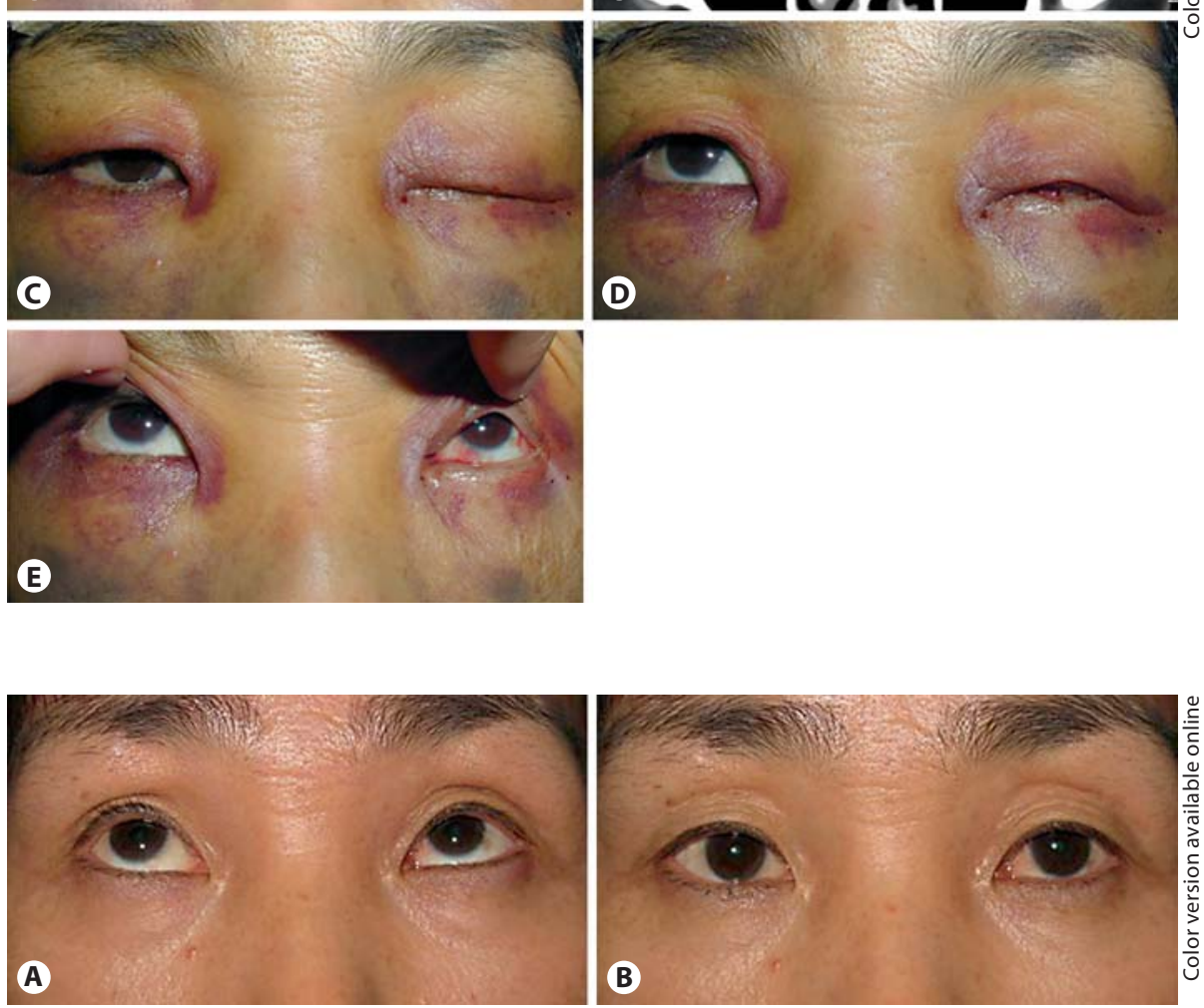

Fig. 2. Upgaze (A) and primary gaze (B) 1 month after orbital wall reconstruction: complete improvement of ptosis on the left upper eyelid.

were assessed preoperatively and then postoperatively every week until 1 month after the operation followed by every month until 6 months after the operation. With only oral steroid therapy, all 3 patients began to improve within 2 weeks and recovered completely, regaining their normal symmetric eyelid position and levator function or preoperative state within 1 month (fig. 2).

\section{Discussion}

Acquired postoperative blepharoptosis [5] is a wellrecognized complication of anterior segment surgery. Paris and Quickert [5] stated that the most common rate of this complication after cataract surgery is $1-2 \%$. However, a search of the Medline database (search words used: blepharoptosis, orbital surgery complication, orbital wall reconstruction complications) showed that no studies have been published about postoperative blepharoptosis related to orbital surgery. We treated 472 cases of orbital medial wall fractures at the Gachon University, Gil Med- ical Center, between September 2000 and October 2005, and the operations were performed by 3 surgeons using a single method. In that time, we experienced 3 cases of unilateral blepharoptosis $(0.6 \%)$ postoperatively. The mechanism by which this condition develops appears to be neurogenic, as evidenced by the complete loss of levator function with minimal eyelid edema. In such cases, ptosis is caused by the involvement of the superior division of the oculomotor nerve, which innervates the superior rectus muscle on its inferior surface before terminating in the overlying levator palpebrae superioris muscle [6]. Given that there is no loss of superior rectus muscle function, the site of injury is presumed to be the oculomotor nerve branch to the levator palpebrae superioris muscle at or near its insertion, and to result from stretching with excessive manipulation. In our cases, all 3 patients underwent reconstruction for medial wall fracture. Such fractures are more difficult to reduce than inferior wall fractures, due to bleeding, poor surgical exposure, 
and technical problems and, therefore, more excessive manipulations with surgical instruments were required. Especially the size of the fracture was so large in these 3 cases as to reach the superior orbital wall, with the result that more complicated techniques were needed. These excessive manipulations may cause ischemic damage to the superior branch of the oculomotor nerve. Our patients completely recovered with normal symmetric eyelid positions and levator function after initial high-dose steroid pulse therapy followed by gradual tapering off for a month, and there was no recurrence during the 6-month follow-up period after the operation. It is believed that a massive dose of steroids provides an antioxidant effect, thereby protecting the neural tissues from the free radical damage that usually occurs after ischemic injury [7]. However, it was not clear whether cortisone can cause a recovery. So, the possibility of spontaneous recovery should be considered.

In summary, isolated neurogenic blepharoptosis after orbital medial wall reconstruction is a rare but favorable disease that may result from ischemic damage at the end portion of the superior branch of the oculomotor nerve in the orbit. High-dose steroid therapy early in the course of the disease was effective, and complete resolution was achieved within 1 month.

\section{References}

1 McCulley TJ, Kersten RC, Yip CC, Kulwin DR: Isolated unilateral neurogenic blepharoptosis secondary to eyelid trauma. Am J Ophthalmol 2002;134:626-627.

2 Small KW, Buckley EG: Recurrent blepharoptosis secondary to a pituitary tumor. Am J Ophthalmol 1998;106:760-761.
3 Yen MY, Liu JH, Jaw SJ: Ptosis as the early manifestation of pituitary tumor. Br J Ophthalmol 1990;74:188-191.

4 Good EF: Ptosis as the sole manifestation of compression of the oculomotor nerve by an aneurysm of the posterior communicating artery. J Clin Neuroophthalmol 1990;10:5961.

5 Paris GL, Quickert MH: Disinsertion of the aponeurosis of the levator palpebrae superioris muscle after cataract extraction. Am J Ophthalmol 1976;81:337-340.
6 Derakhshan I: Superior branch palsy of the oculomotor nerve with spontaneous recovery. Ann Neurol 1978;4:478-479.

7 Brent BD, May DR: Orbital apex syndrome after penetrating orbital trauma. Ann Ophthalmol 1990;22:267-268. 